\title{
Grade Dependent Expression of Growth Factor Receptors and Signaling Molecules in Breast Cancer*
}

\author{
Chellakkan Selvanesan Benson ${ }^{1}$, Somasundaram Dinesh Babu ${ }^{1}$, Selvi Radhakrishna ${ }^{2}$, \\ Nagarajan Selvamurugan ${ }^{3}$, Bhaskaran Ravi Sankar ${ }^{1 \#}$ \\ ${ }^{1}$ Department of Endocrinology, Dr. ALM Post Graduate Institute of Basic Medical Sciences, University of Madras, Taramani Cam- \\ pus, Chennai, India; ${ }^{2}$ Chennai Breast Centre, Chennai, India; ${ }^{3}$ Department of Biotechnology, School of Bioengineering, SRM Uni- \\ versity, Kattankulathur, India. \\ Email: "bensoncs@gmail.com
}

Received May $16^{\text {th }}, 2013$; revised June $18^{\text {th }}, 2013$; accepted June $25^{\text {th }}, 2013$

Copyright (C) 2013 Chellakkan Selvanesan Benson et al. This is an open access article distributed under the Creative Commons Attribution License, which permits unrestricted use, distribution, and reproduction in any medium, provided the original work is properly cited.

\begin{abstract}
Growth factor signaling plays a key role in the growth and development of breast. Aberrant expression and activation of growth factors like insulin like growth factor-I (IGF-I) and epidermal growth factor (EGF) and their downstream signaling has been implicated in breast cancer. The deregulation of growth factor signaling is associated with increased proliferation and cell survival, decreased apoptosis, invasion, angiogenesis and metastasis. The aim of the present study is to survey the different signaling molecules involved in the IGF and EGF signaling pathways, and to find if there are any relationship between breast cancer and their levels and activation. Thirty-nine samples of breast cancer tissues (24 Grade II and 15 Grade III tumours) and sixteen normal breast tissue samples were collected. The expression of the receptors and signaling molecules were investigated using Western blot. IGF-IR $\beta$, AR, pAkt, IKK- $\alpha$ and $\mathrm{p} 38$ are upregulated in cancer tissues in a grade depended manner. Further, Akt and $\beta$-catenin were also upregulated in cancer samples. Correlation analysis of signaling molecules revealed a disruption in their expression in cancer tissues. The present study shows that various signaling molecules are upregulated or activated in cancer tissues involving IGF-IR and Akt pathway. The expression of signaling molecules in the cancer tissues were deregulated when compared to the control samples. Thus, flawed expression and over activation of Akt pathway is seen in the breast cancer tissues.
\end{abstract}

Keywords: Breast Cancer; Growth Factors; IGF-IR; EGF-R; Cancer Grade; Steroid Receptor

\section{Introduction}

Breast cancer is a worldwide health concern for women. Growth factors stimulate cellular growth, proliferation and differentiation and are vital for the normal development and function of the breast [1]. In breast cancer, insulin-like growth factor (IGF) and epidermal growth factor (EGF) signaling systems are affected leading to abnormal mitogenicity and cell survival. Further, estrogen act synergistically with growth factors to enhance the mitogenic effect of growth factors by inducing expression of several members of the IGF and EGF family [2].

IGF signaling system plays a critical role in the growth and development of many tissues. However, IGF system

\footnotetext{
*The work was supported by Department of Science and Technology, INSPIRE, IF 10052.

${ }^{\#}$ Corresponding author.
}

is also implicated in various pathophysiological conditions and is thought to play a prominent role in tumorigenesis [3]. High serum IGF-I levels predict an increased risk of breast cancer [4]. Both experimental and clinical studies have demonstrated that IGF-IR is overexpressed in cancer cells compared with normal tissues [5]. EGF receptor (EGFR) has been considered a nodal point which converges many cytokine and hormone-induced signals to lead to MAPK activation [6]. EGFR signaling can induce epithelial to mesenchymal transition, invasion, and metastasis in different cancer cell types, including human breast cancer cells [7].

Downstream signaling of growth factors involves Akt and ERK pathways which consist of an array of signaling molecules. Akt signaling pathway regulates diverse biological functions, including cellular proliferation, survival, and motility in cancer cells. Glycogen synthase 
kinase $3 \beta(\mathrm{GSK}-3 \beta)$, a downstream molecule of Akt, is a key target of PI 3-kinase signaling leading to prevention of apoptosis [8]. $\beta$-catenin was a poor prognostic marker in human cancer and was implicated in human breast cancer. There is a strong correlation between $\beta$-catenin activity and cyclin D1 expression in both breast cancer cell lines and breast patient tissue samples and it also known to activate MMP-7 during cancer [9]. ERK is largely activated by growth factor signals [10]. Elevated MAPK activation was found in breast carcinoma compared with benign breast tissue [11]. The p38 MAPKs have also been shown to play roles in cell proliferation and survival. p38 MAPK also plays a role in the downstream signaling of VEGF leading to angiogenesis [12]. $\mathrm{NF}-\kappa \mathrm{B}$ has also been shown to be involved in the development of carcinomas, cancers of epithelial origin, such as breast cancer. The activation of NF- $\kappa \mathrm{B}$ is controlled by IKK- $\alpha$ and IKK- $\beta$, by canonical pathway, NF- $\kappa \mathrm{B}$ plays a major role in inflammation, cell survival, transformation, and oncogenesis in breast cancer [13].

Breast cells are also under steroid hormone regulation with estrogen and progesterone controlling the rate of mitosis [14]. Estrogen receptors (ERs) belong to the ligand regulated transcription factors that transduce hormone signals into a large variety of physiological responses in various organs including breast. Both the genomic and non-genomic actions of estrogen play pivotal roles in E2-induced cancer cell proliferation and survival [15]. The role of the androgen receptor (AR) in breast carcinomas has drawn great attention in recent years, especially due to its expression in ER and PR negative breast carcinomas [16]. Epidemiologic studies showed that increased serum androgen level was associated with an increased risk for breast cancer in postmenopausal patients [17]. Hanley et al. investigated the potential role of AR in relation to breast tumor progression and showed that $93 \%$ of 43 high-grade ductal carcinoma in situ cases expressed AR, whereas only $55 \%$ of 44 high grade invasive ductal carcinomas showed AR expression showing a grade dependent upregulation [18].

Thus several growth factor pathways and steroid receptors play various roles in cancer progression. Our objective for this study was is to survey the protein levels of the signaling molecules involved in the IGF and EGF signaling pathways along with ER and AR, and to find if there are any relationship between the breast cancer and the levels and activation of key signaling molecules.

\section{Materials and Methods}

\subsection{Tissue Samples}

The study was performed with approval of the Ethics Committee of the University of Madras, India, (Ref No: PGIBMS/CO/Human Ethical/2009-10/353) and was car- ried out in accordance with the Helsinki declaration of 2000 of the World Medical Association. Breast tumor removal surgeries were performed by a trained breast cancer surgeon (S.R) at Chennai Breast Centre, Chennai, India. Thirty-nine samples of breast cancer tissue (24 Grade II and 15 Grade III tumours) and sixteen normal breast tissue samples were obtained. Normal breast tissues were obtained from outside the tumor margin and these tissues were analysed histologically to exclude them from any forms of malignancy or other pathological findings (Data not shown).

\subsection{Western Blotting}

For protein extraction, $50 \mathrm{mg}$ of tissue samples were lysed in pre-cooled RIPA-buffer containing phosphatase inhibitors (Pierce Biotechnology Inc, USA), proteinase inhibitors (Roche, Germany). Equal amount of total protein $(35 \mu \mathrm{g})$ was mixed with $2 \mathrm{X}$ sample buffer and boiled for $5 \mathrm{~min}$. The protein was separated on $10 \%$ SDS-PAGE and electrotransfered onto a PVDF membrane (Bio-Rad, USA). To avoid non-specific binding, membranes were blocked with $5 \%$ non-fat milk protein in PBS/Tween at RT for 3 hours. After blocking, membranes were incubated with respective rabbit polyclonal antibodies (Cell signaling Technologies, USA) pAkt (\#9271S), Akt (\#4685), pERk (\#1972), Erk (\#9102), pGSK (\#9336), GSK (\#9315), IKK- $\alpha$ (\#2682), IKK- $\beta$ (\#2684), $\beta$-catanin (\#9562), p38 (\#9212), IGF-IR $\beta$ (\#3027), EGRF (\#4267), $\mathrm{ER} \alpha$ (sc-543), and AR (sc-815), in 1:2000 dilution for overnight at $4{ }^{\circ} \mathrm{C}$. For mouse monoclonal $\beta$-actin antibody in 1:5000 dilutions. Finally, signals were visualized using Enhanced Chemiluminescent System (Pierce Biotechnology Inc., USA) and the signals were captured by Chemi Doc XRS system (Bio Rad, USA) and the intensity of the bands were quantified by Quantity One software (Bio Rad, USA).

\subsection{Data Analysis and Statistics}

Protein expression data from normal (control) and cancer tissues were analysed by Kruskal-Wallis test followed by Mann-Whitney test. Protein expression data was further subjected to Pearson correlation analysis to identify the correlations between the signaling molecules within the control and within the cancer samples respectively. Correlation analysis for cancer samples were performed by pooling data from Grade II and Grade III. To analyse if there are any differences in the correlation coefficients between control and cancer tissues Fisher transformation analysis was performed for correlation coefficients with $\mathrm{r}>$ 0.8. SPSS 17.0 software package was used for data analysis and Graph Pad prism 5.0 software was used to draw graphs. Fisher transformation analysis was done using 
MedCalc software. Data was considered statistically significant when $\mathrm{p}<0.05$.

\section{Results}

\subsection{Patients Data}

In the present study, we analysed 24 Grade II samples and 15 Grade III samples from patients of age range from 29 to 85 with a mean age of 56 years. The patient data is summarized in Table 1. The patients with Grade II tumour had bigger tumour size and the nodal status had no difference between the groups. More patients in Grade III tumour had lymph node metastasis at the time of diagnosis. The distribution of the estrogen receptor (ER), progesterone receptor (PR) and human epidermal growth factor receptor 2 (HER2) statuses is shown in Figures 1(a) and (b). The ER, PR and HER2 status was done by immunohistochemistry.

\subsection{IGF-IR $\beta$ and EGF-R Levels in Control and Breast Cancer Samples}

IGF-IR $\beta$ is highly expressed in cancer and its protein level increased in Grade II $(p<0.001)$ and Grade III ( $p$ $<0.0001$ ) when compared to control. There was no difference in the IGF-IR $\beta$ levels between Grade II and Grade III cancer samples (Figures 2 and 3(a)). Our data also show that IGF-IR $\beta$ levels where upregulated in $87.2 \%$ of the cancer samples (Table 2). EGF-R protein levels are upregulated in cancer grade III $(\mathrm{p}<0.003)$ when compared to Grade II but did not show any difference when compared to the controls (Figures 2

Table 1. G2: moderately differentiated tumor; G3: poorly differentiated; $T$ : tumor grade; $N$ : nodal status; L: invasion of lymphatic vessels.

\begin{tabular}{|c|c|c|}
\hline Age & Grade II & Grade III \\
\hline Minimum & & \\
\hline Maximum & & \\
\hline Mean & & \\
\hline \multicolumn{3}{|c|}{ T (Tumor Size) } \\
\hline 1 & 3 & 1 \\
\hline 2 & 18 & 12 \\
\hline 3 & 1 & 0 \\
\hline 4 & 2 & 1 \\
\hline Not Known & 0 & 1 \\
\hline \multicolumn{3}{|c|}{ N (Nodal Status) } \\
\hline 0 & 11 & 5 \\
\hline 1 & 5 & 3 \\
\hline 2 & 5 & 1 \\
\hline 3 & 2 & 4 \\
\hline $\mathrm{X}$ & 1 & 1 \\
\hline Not Known & 0 & 1 \\
\hline \multicolumn{3}{|c|}{ L (Invasion of Lymphatic Vessel) } \\
\hline 0 & 10 & 7 \\
\hline 1 & 8 & 6 \\
\hline $\mathrm{X}$ & 6 & 1 \\
\hline Not Known & 0 & 1 \\
\hline
\end{tabular}

and $3(\mathbf{b})$ ). However, it is interesting to note that $59 \%$ of the cancer patients had elevated levels of EGF-R when compared to the controls (Table 2) and $80 \%$ of Grade III patients have elevated levels of EGF-R (Table 2).

\subsection{Expression of Signaling Molecules Downstream to IGF and EGF}

The Akt protein level increased in Grade II $(\mathrm{p}<0.003)$ when compared with control whereas pAkt levels showed increase in Grade III $(\mathrm{p}<0.001)$ when compared to the control and showed a grade dependent increasing tendency (Figures 2, 3(c) and (d)). Akt and pAkt levels were more than the control levels in $71.8 \%$ and $69.2 \%$ of the cancer patients respectively (Table 2). Neither ERK nor its phosphorylation levels show any difference between the control and the cancer tissue (Figures 2, 3(e) and (f)). Similar observations were seen in the levels of

Table 2. Percentage of up and down regulation of signaling molecules and receptors in cancer samples when compared with control.

\begin{tabular}{|c|c|c|c|}
\hline Signaling Molecules & Grade II & Grade III & $\begin{array}{c}\text { Grade II and } \\
\text { Grade III }\end{array}$ \\
\hline \multirow{2}{*}{ IGF-R } & $16.7 \% \downarrow$ & $6.7 \% \downarrow$ & $12.8 \% \downarrow$ \\
\hline & $83.3 \% \uparrow$ & $93.3 \% \uparrow$ & $87.2 \% \uparrow$ \\
\hline \multirow{2}{*}{ EGF-R } & $54.2 \% \downarrow$ & $20.0 \% \downarrow$ & $41.0 \% \downarrow$ \\
\hline & $45.8 \% \uparrow$ & $80.0 \% \uparrow$ & $59.0 \% \uparrow$ \\
\hline \multirow{2}{*}{ pAkt } & $41.7 \% \downarrow$ & $13.3 \% \downarrow$ & $30.8 \% \downarrow$ \\
\hline & $58.3 \% \uparrow$ & $86.7 \% \uparrow$ & $69.2 \% \uparrow$ \\
\hline \multirow{2}{*}{ Akt } & $20.8 \% \downarrow$ & $40 \% \downarrow$ & $28.2 \% \downarrow$ \\
\hline & $79.2 \% \uparrow$ & $60 \% \uparrow$ & $71.8 \% \uparrow$ \\
\hline \multirow{2}{*}{ pERK } & $65 \% \downarrow$ & $71.4 \% \downarrow$ & $67.6 \% \downarrow$ \\
\hline & $35 \% \uparrow$ & $28.6 \% \uparrow$ & $32.4 \% \uparrow$ \\
\hline \multirow{2}{*}{ ERK } & $29.2 \% \downarrow$ & $33.3 \% \downarrow$ & $30.8 \% \downarrow$ \\
\hline & $70.8 \% \uparrow$ & $66.7 \% \uparrow$ & $69.2 \% \uparrow$ \\
\hline \multirow{2}{*}{ pGSK } & $83.3 \% \downarrow$ & $46.7 \% \downarrow$ & $69.2 \% \downarrow$ \\
\hline & $16.7 \% \uparrow$ & $53.3 \% \uparrow$ & $30.8 \% \uparrow$ \\
\hline \multirow{2}{*}{ GSK } & $79.2 \% \downarrow$ & $60 \% \downarrow$ & $71.8 \% \downarrow$ \\
\hline & $20.8 \% \uparrow$ & $40 \% \uparrow$ & $28.2 \% \uparrow$ \\
\hline \multirow{2}{*}{ IKK- $\alpha$} & $16.7 \% \downarrow$ & $6.7 \% \downarrow$ & $12.8 \% \downarrow$ \\
\hline & $83.3 \% \uparrow$ & $93.3 \% \uparrow$ & $87.2 \% \uparrow$ \\
\hline \multirow{2}{*}{$\mathrm{IKK}-\beta$} & $62.5 \% \downarrow$ & $46.7 \% \downarrow$ & $56.4 \% \downarrow$ \\
\hline & $37.5 \% \uparrow$ & $53.3 \% \uparrow$ & $43.6 \% \uparrow$ \\
\hline \multirow{2}{*}{ p38 } & $25 \% \downarrow$ & $13.3 \% \downarrow$ & $20.5 \% \downarrow$ \\
\hline & $75 \% \uparrow$ & $86.7 \% \uparrow$ & $79.5 \% \uparrow$ \\
\hline \multirow{2}{*}{$\beta$-catenin } & $16.7 \% \downarrow$ & $13.3 \% \downarrow$ & $15.4 \% \downarrow$ \\
\hline & $83.3 \% \uparrow$ & $86.7 \% \uparrow$ & $84.6 \% \uparrow$ \\
\hline \multirow{2}{*}{$\mathrm{ER} \alpha$} & $20.8 \% \downarrow$ & $6.7 \% \downarrow$ & $15.4 \% \downarrow$ \\
\hline & $79.2 \% \uparrow$ & $93.3 \% \uparrow$ & $84.6 \% \uparrow$ \\
\hline \multirow{2}{*}{ AR } & $25 \% \downarrow$ & $0 \% \downarrow$ & $15.4 \% \downarrow$ \\
\hline & $75 \% \uparrow$ & $100 \% \uparrow$ & $84.6 \% \uparrow$ \\
\hline
\end{tabular}



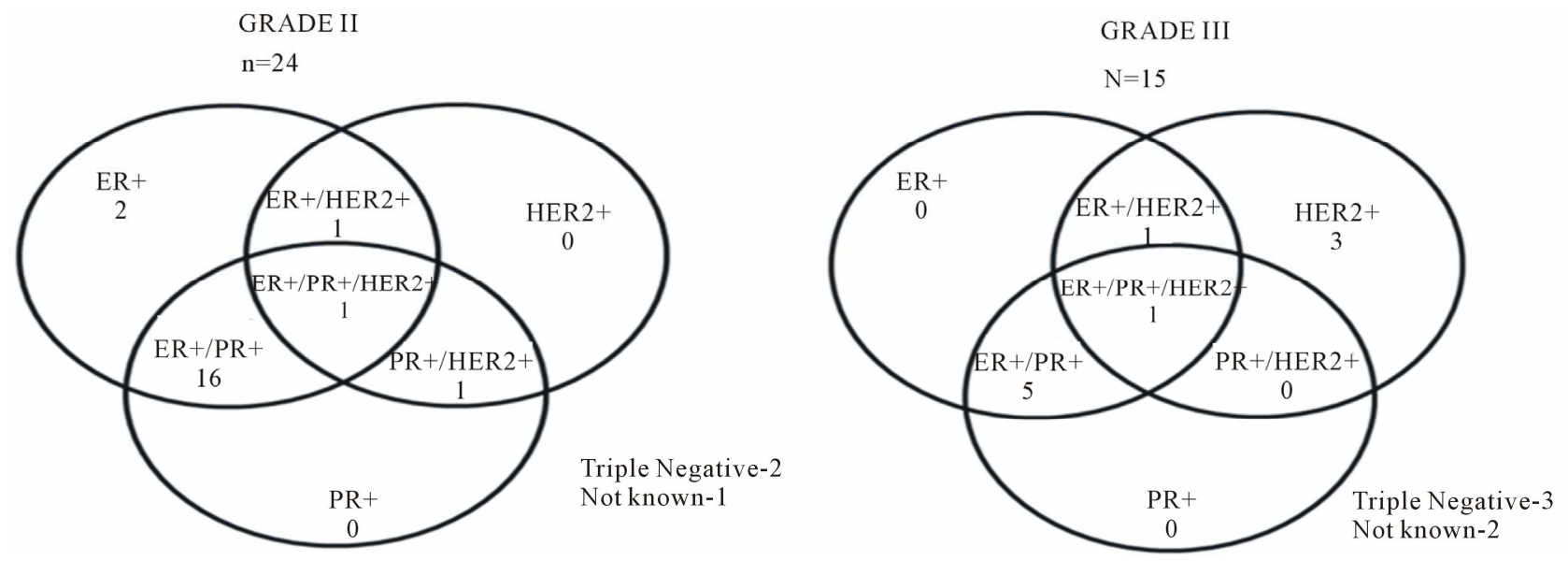

Figure 1. Venn diagram shows the presence of ER, PR and HER2 and their distribution among the samples in Grade II (Figure 1(a)) and Grade II (Figure 1(b)) breast cancer tissues.

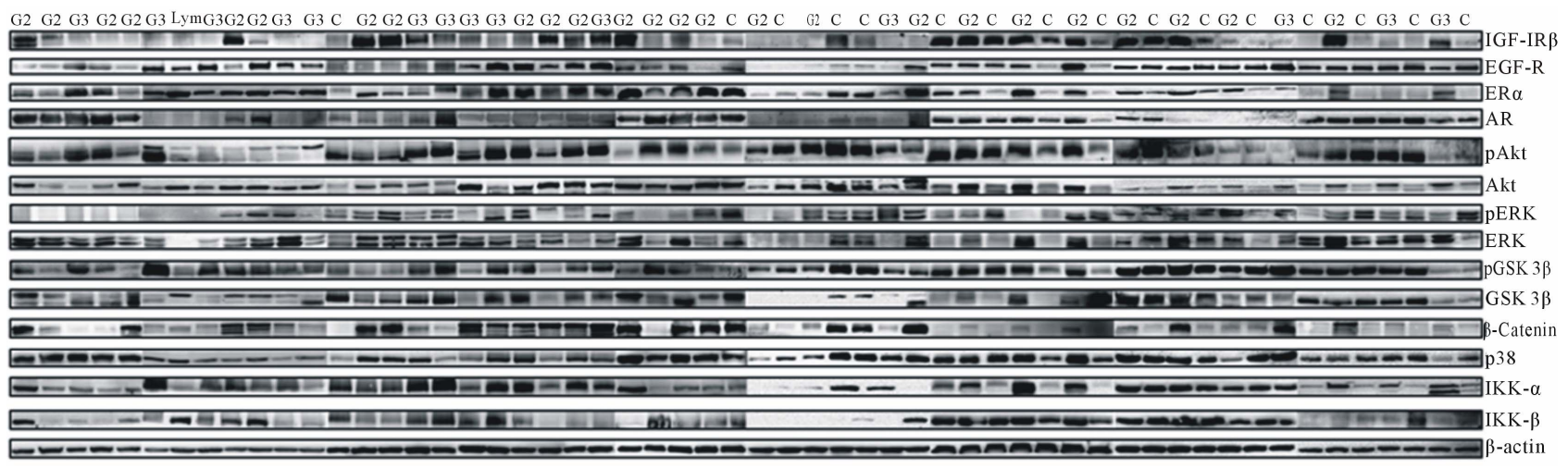

Figure 2. Protein lysates were isolated from normal breast (Control), breast cancer tissue Grade II (G2) and breast cancer tissue Grade II (G3). Protein samples were separated by polycrylamide gel electropgoresis and expression of proteins was visualized using specific antibodies. $\beta$-actin was used as internal loading control.

GSK and pGSK (Figures 2, 3(g) and (h)). IKK- $\alpha$ levels increased in cancer Grade II $(p<0.01)$ and Grade III $(p<$ 0.001 ) when compared to controls showing a grade dependent increase with $87.2 \%$ (Table 2) of samples in cancer patients showing upregulation (Figures 2 and 3(i)). However, IKK- $\beta$ did not display any changes (Figures 2 and $\mathbf{3}(\mathbf{g}),(\mathbf{j}))$. The levels of p38 protein was higher in Grade II $(p<0.013)$ and in Grade III $(p<0.001)$ when compared with control (Figures 2 and 3(k)) with $79.5 \%$ of the cancer samples showing upregulation (Table 2). $\beta$-catenin also showed similar pattern with higher protein levels in Grade II $(\mathrm{p}<0.031)$ and Grade III $(\mathrm{p}<0.053)$ when compared to controls (Figures 2 and $3(\mathbf{l})$ ). Further, $84.6 \%$ of the cancer samples displayed upregulation when compared to the control samples (Table 2).

\section{4. $\mathrm{ER} \alpha$ and $\mathrm{AR}$ in Different Stages of Breast Cancer}

The ER $\alpha$ expression did not show any difference be- tween control and cancer tissues but showed an upregulating tendency (Figures 2 and 4(a)). In $84.6 \%$ of the samples ER $\alpha$ expression was higher than the control samples (Table 2). AR expression progressively increased in Grade II $(p<0.002)$ and in Grade III $(p<0.0001)$ when compared with control (Figures 2 and $\mathbf{4 ( b ) )}$ ). It is interesting to note that AR levels were upregulated $84.6 \%$ of cancer samples when compared to the controls (Table 2).

\subsection{Correlation between Signaling Molecules in Control and Cancer Tissues}

Pearson correlation analysis was performed to find inter-relationship of the signaling molecules/receptors in control samples and to identify if this relationship is altered in cancer tissues. Results clearly indicate that correlation exists between the levels of various signaling molecules in the control samples (Table 3). There is a strong positive $(r>0.8)$ correlation between the levels of pERK and IKK- $\beta(\mathrm{p}<0.001, \mathrm{r}=$ 


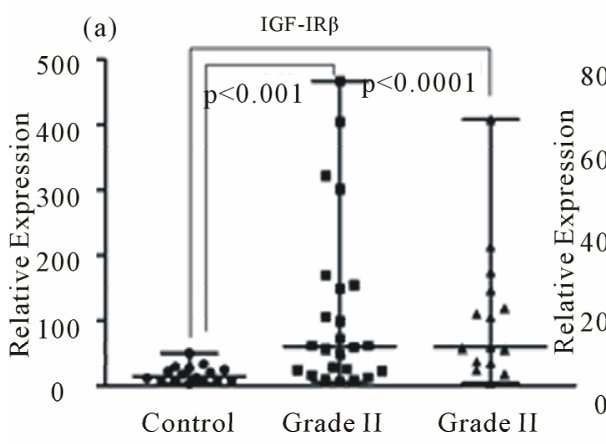

(b)

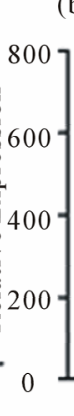

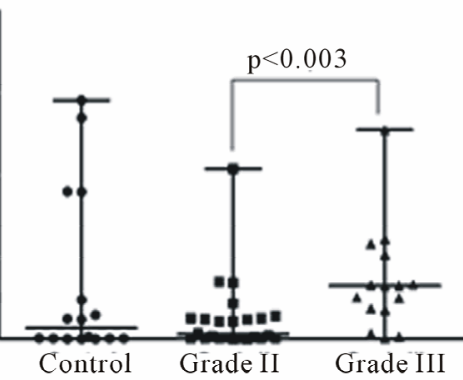

(c)

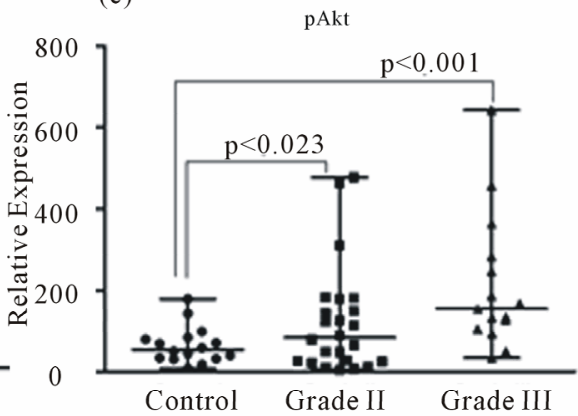

(d)

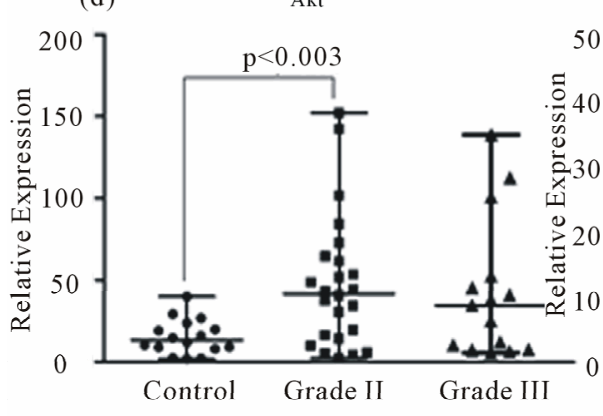

(e)

pERK

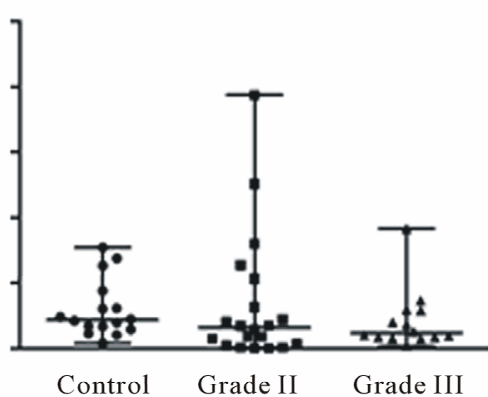

(f)

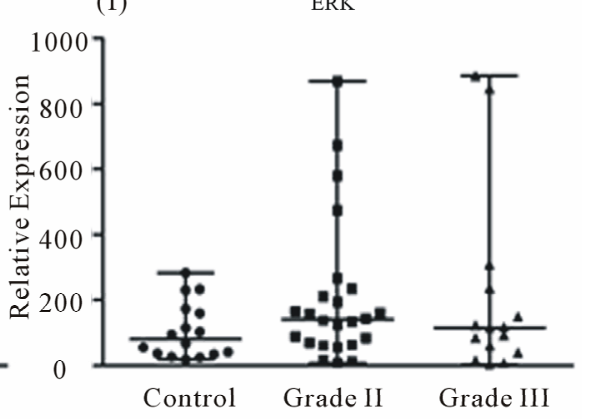

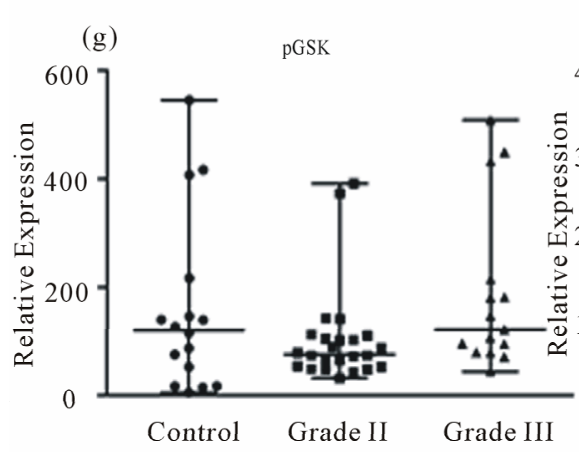

(h)

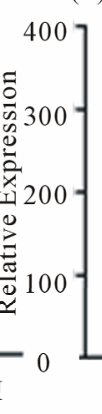

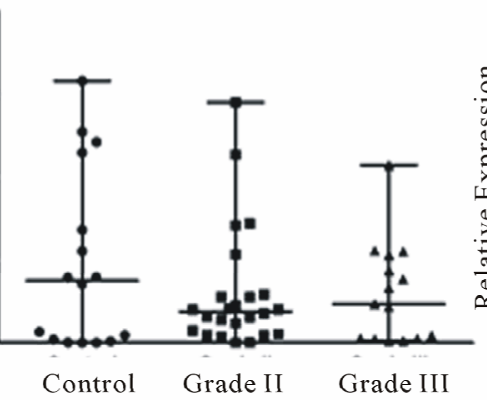
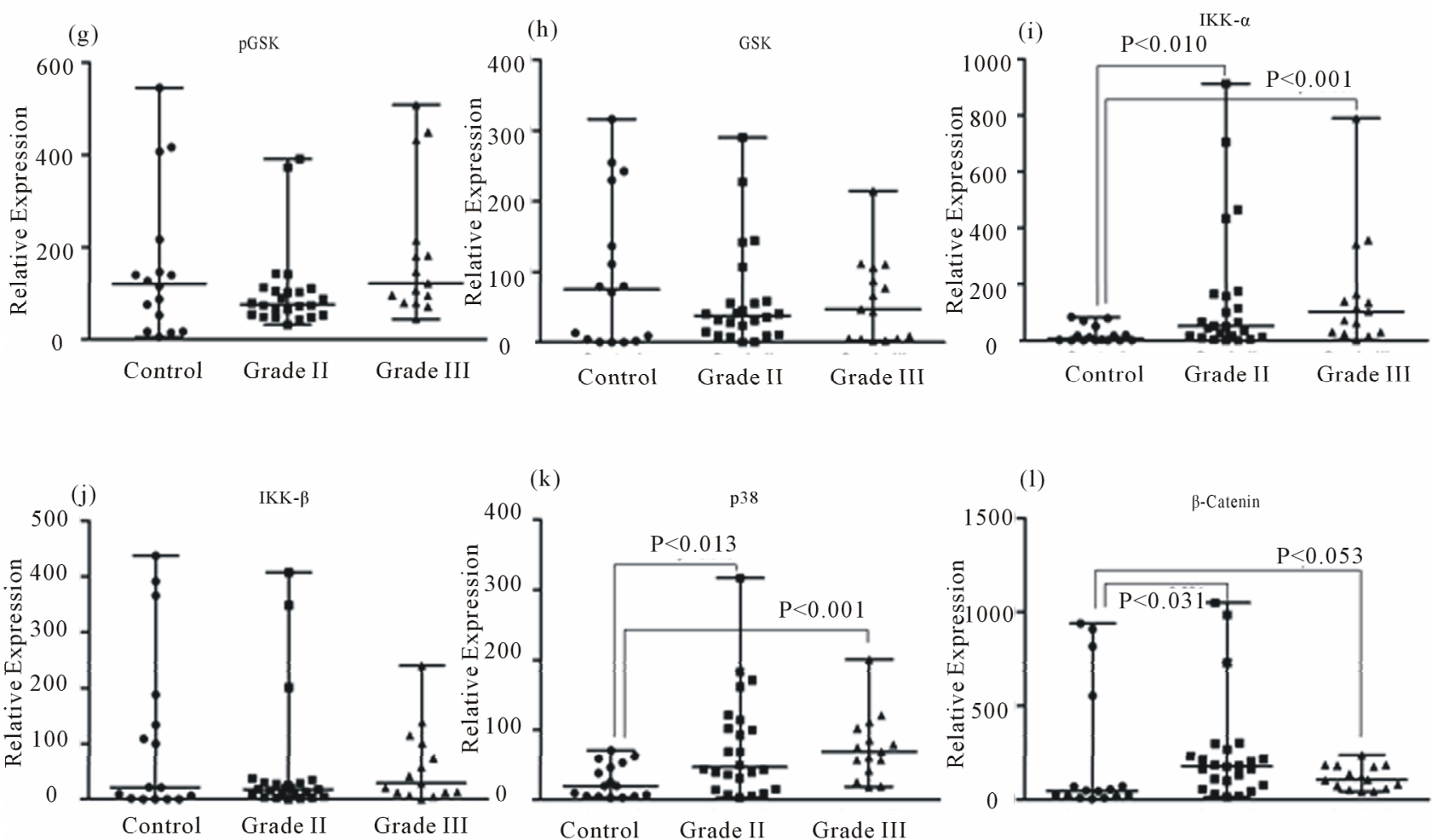

$(\mathrm{k})$

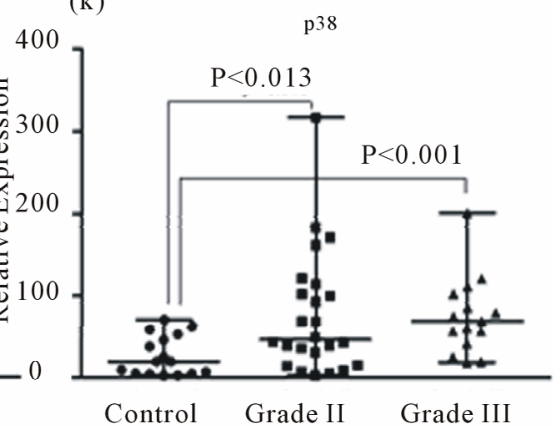

(1)

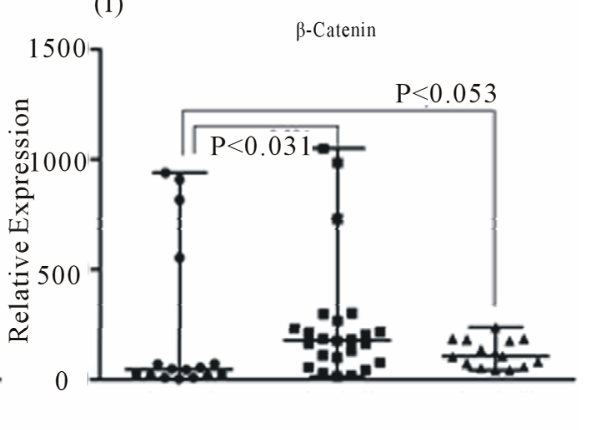

Figure 3. Dot plot analysis of densitometrically quantified expression of IGF-IRß(a), EGF-R(b), pAk, Akt(d), pERK(e), ERK(f), pGSK3 $\beta($ g), GSK3 $\beta(\mathbf{h})$, IKK- $\alpha(\mathrm{i})$, IKK- $\alpha(\mathrm{j}), \beta$-catenin(k), p38(l). Protein levels were normalized to the corresponding expression of $\beta$-actin. For each protein three dotplots are mapped, Control, Grade II and Grade III. The line within the dot plot corresponds to the median value, and bars indicate the smallest and largest observations. Comparison of expression values between the groups was performed by Kruskal-Wallis test followed by Mann-Whitney test. p values $<0.05$ were considered as statistically significant. 

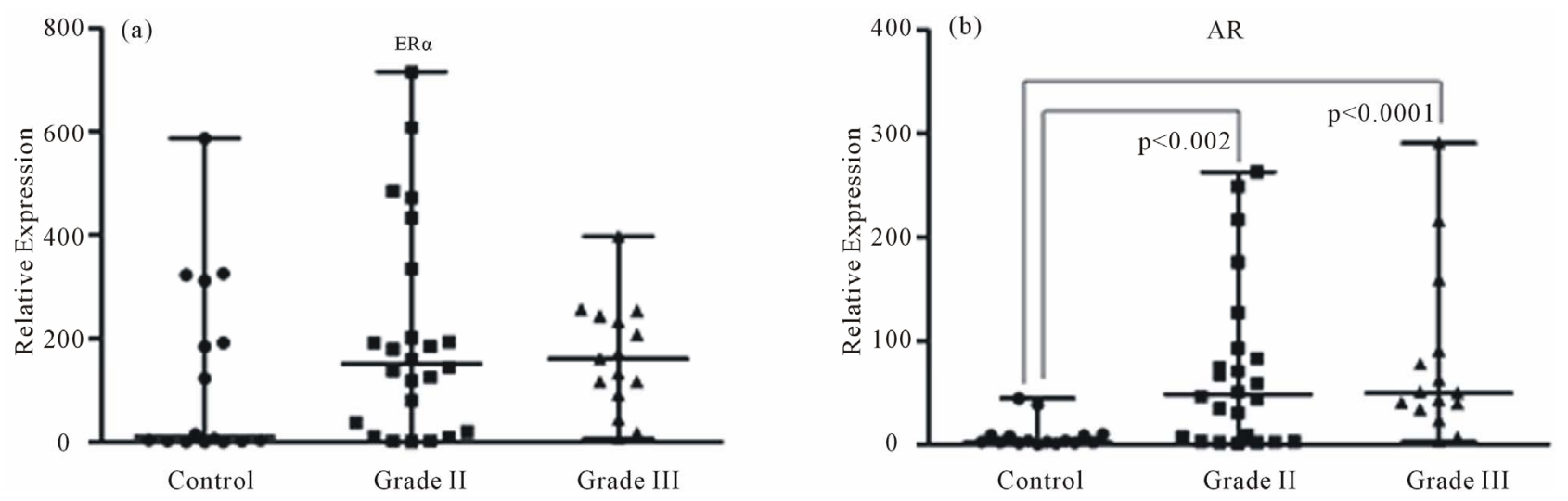

Figure 4. Dot plot analysis of densitometrically quantified expression of AR and ER- $\alpha$. Protein levels were normalized to the corresponding expression of $\beta$-actin. For each protein three dot plots are mapped, Control, Grade II and Grade III. The line within the dot plot corresponds to the median value, and bars indicate the smallest and largest observations. Comparison of expression values between the groups was performed by Kruskal-Wallis test followed by Mann-Whitney test. p values $<0.05$ were considered as statistically significant.

0.824), pGSK and $\beta$-catenin $(\mathrm{p}<0.001, \mathrm{r}=0.802)$, pGSK and ER $\alpha(\mathrm{p}<0.001, \mathrm{r}=0.825), \mathrm{pGSK}$ and IGF-R $(\mathrm{p}<0.001, \mathrm{r}=0.849), \mathrm{pGSK}$ and EGF-R $(\mathrm{p}<0.001, \mathrm{r}=$ $0.855)$, GSK and $\mathrm{p} 38(\mathrm{p}<0.001, \mathrm{r}=0.839)$, IKK- $\alpha$ and $\beta$-catenin $(\mathrm{p}<0.001, \mathrm{r}=0.901), \mathrm{IKK}-\alpha$ and ER $\alpha(\mathrm{p}<$ $0.001, \mathrm{r}=0.893)$, IKK- $\alpha$ and EGF-R $(\mathrm{p}<0.001, \mathrm{r}=$ $0.885), \beta$-catenin and $\operatorname{ER} \alpha(\mathrm{p}<0.001, \mathrm{r}=0.896)$, $\beta$-catenin and IGF-R $(\mathrm{p}<0.001, \mathrm{r}=0.830), \beta$-catenin and EGF-R $(\mathrm{p}<0.001, \mathrm{r}=0.978), \mathrm{ER} \alpha$ and IGF-R $(\mathrm{p}<$ $0.001, \mathrm{r}=0.846), \mathrm{ER} \alpha$ and IGF-R $(\mathrm{p}<0.001, \mathrm{r}=0.898)$ and IGF-R and EGF-R ( $p<0.001, r=0.828)$ in the cancer free control tissue. Interestingly, a new correlation emerged between IKK- $\alpha$ and IKK- $\beta$ ( $\mathrm{p}<0.001, \mathrm{r}=$ 0.850), (Table 4). Further, comparison of corresponding correlation coefficients between control and cancer samples reveal that almost all except the correlations seen between IKK $\alpha$ vs. ER $\alpha$, and $\beta$-catenin vs. IGF-IR in the control samples are lost in the cancer tissues (Table 5).

\section{Discussion}

Growth factor signaling plays a vital role in the cancer progression cellular proliferation and metastasis. Substantial evidences implicate IGF signaling in the development and progression of many cancers, including breast cancer [19] and upregulation of IGF-I is often associated with poor prognosis [4]. The present study shows a grade dependent upregulation of IGF-IR in cancer tissues. Similar IGF-IR upregulation in cancer tissues were previously reported in Canadian population. Further, correlation analysis within the control and cancer samples show that in normal breast tissues IGF-IR has a positive correlation with GSK, $\beta$-catenin and ER $\alpha$, but the correlation between IGF-IR and GSK, and IGF-IR and $\mathrm{ER} \alpha$ was lost in cancer tissues indicating a perturbed expression of signaling molecules in cancer cells.

Over expression of EGF-R in breast cancer is associated with large tumor size, poor differentiation and poor clinical outcomes. Further, EGF-R over expression has been associated with higher grade and extensive forms of ductal carcinoma in situ [20]. Although in the present study EGF-R did not increase in cancer tissues, it is important to note that its levels were upregulated in $80 \%$ of the Grade III patients. Similar upregulation of EGF-R inhigher grade cancer was has been reported [20]. Correlation analysis shows that in control samples EGF-R is positively correlated with pGSK, IKK- $\alpha, \beta$-catenin, ER $\alpha$ and IGF-R, but in cancer tissues EGF-R lost all these correlations suggesting abnormal expression of these molecules which could lead to flawed signaling.

Our study also shows that the expressions of various downstream signaling molecules to the growth factor receptors are affected in cancer tissues. Akt pathway is an important regulator of cell proliferation and survival and is deregulated in breast cancer. In the present study pAkt shows a grade depended increase in cancer, suggesting hyper-activation of Akt molecules in cancer tissues. However, ERK expression and its phosphorylation did not show any increase in cancer tissues and pERK was lower in $67.6 \%$ cancer samples when compared to controls. Thus our data shows an apparent domination of Akt pathway over ERK pathway in cancer tissues. Western blot data shows that downstream signaling molecules of Akt are upregulated in cancer samples. IKK- $\alpha$ is a regulatory molecule of NF- $\kappa \mathrm{B}$, pAkt activates the IKK- $\alpha$ by phosphorylating it, and thereby activating the NF- $\kappa \mathrm{B}$ [21]. Our data shows that there is an upregulation in the overall IKK- $\alpha$ expression and is increased in $87.2 \%$ of the cancer samples indicating an Akt induced IKK- $\alpha$ activation. Activated IKK $-\alpha$ could promote NF- $\kappa$ B mediated transcription [22]. GSK, a downstream signaling 


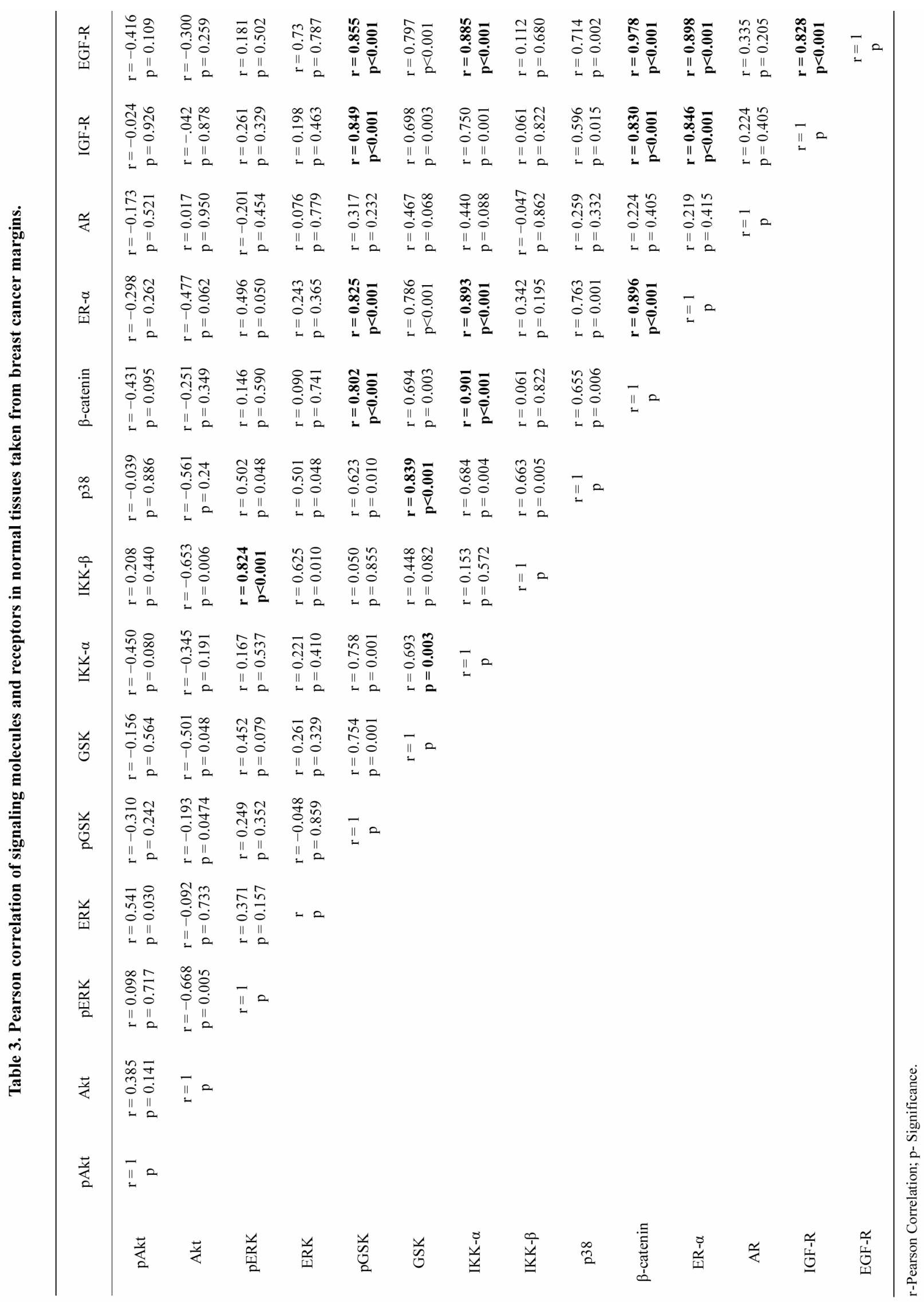




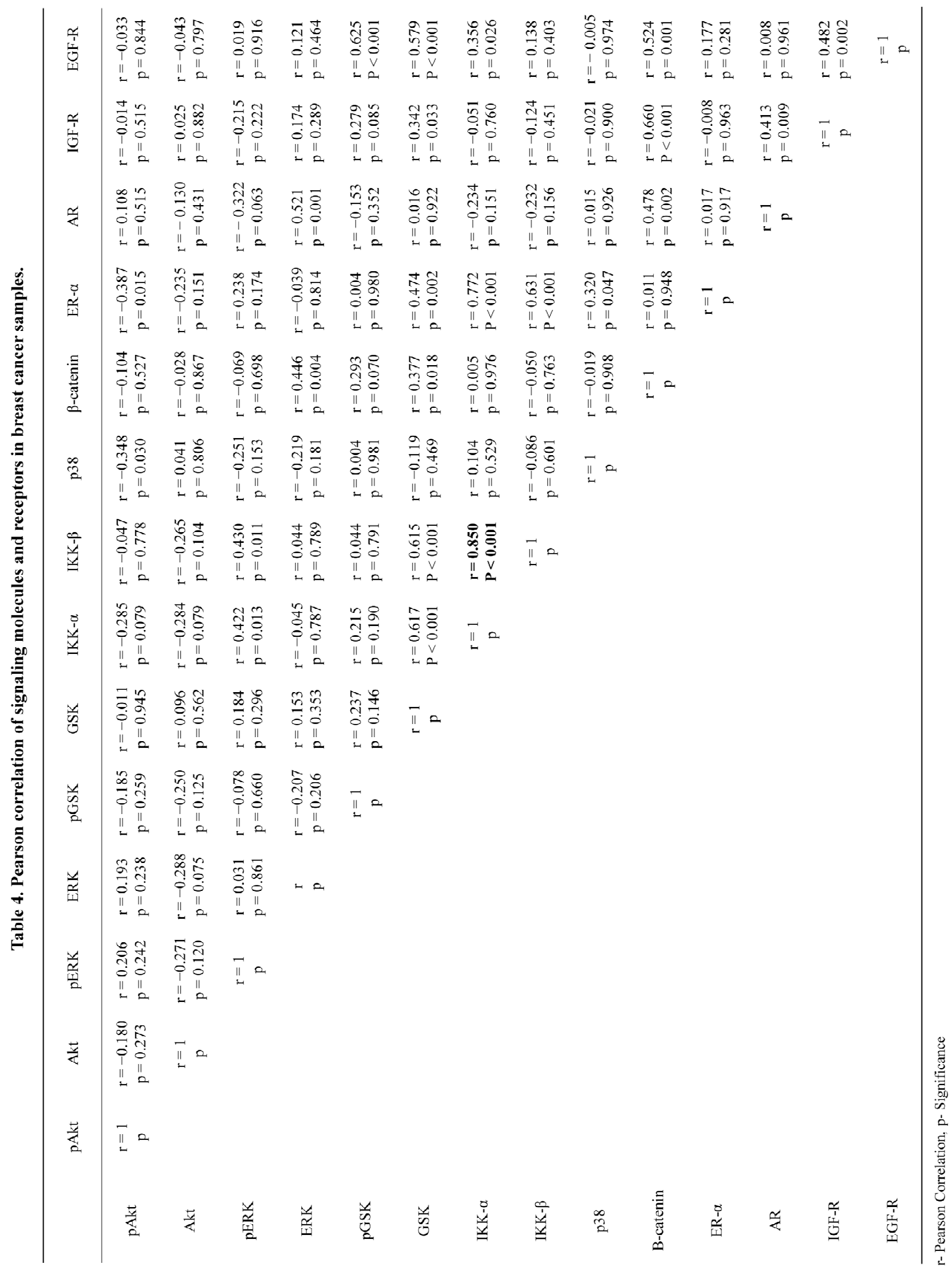


Table 5. Comparison of correlation co-efficients within control and breast cancer tissues (Fisher transformation analysis).

\begin{tabular}{|c|c|c|c|}
\hline \multicolumn{4}{|c|}{ Control } \\
\hline S No & Group & $\mathrm{r}=$ Values & Correlation co-efficient \\
\hline \multirow{2}{*}{1} & Control pERK vs IKK $\beta$ & $\mathrm{r}=0.824$ & $\mathrm{p}=0.028^{*}$ \\
\hline & Cancer pERK vs IKK $\beta$ & $\mathrm{r}=0.430$ & $\mathrm{z}=2.1919$ \\
\hline \multirow{2}{*}{2} & Control GSK vs p38 & $\mathrm{r}=0.839$ & $\mathrm{p}=0.0007^{*}$ \\
\hline & Cancer GSK vs p38 & $\mathrm{r}=0.119$ & $z=3.3940$ \\
\hline \multirow{2}{*}{3} & Control pGSK vs $\beta$-catenin & $\mathrm{r}=0.802$ & $\mathrm{p}=0.0132^{*}$ \\
\hline & Cancer pGSK vs $\beta$-catenin & $\mathrm{r}=0.293$ & $z=2.4797$ \\
\hline \multirow{2}{*}{4} & Control IKK- $\alpha$ vs $\beta$-catenin & $\mathrm{r}=0.901$ & $\mathrm{p}=0.0001^{*}$ \\
\hline & Cancer IKK- $\alpha$ vs $\beta$-catenin & $\mathrm{r}=0.005$ & $z=4.5508$ \\
\hline \multirow{2}{*}{5} & Control pGSK vs ER- $\alpha$ & $\mathrm{r}=0.825$ & $\mathrm{p}=0.0003^{*}$ \\
\hline & Cancer pGSK vs ER- $\alpha$ & $\mathrm{r}=0.004$ & $z=3.6105$ \\
\hline \multirow{2}{*}{6} & Control IKK- $\alpha$ vs ER- $\alpha$ & $r=0.893$ & $\mathrm{p}=0.2037$ \\
\hline & Cancer IKK- $\alpha$ vs ER- $\alpha$ & $\mathrm{r}=0.777$ & $\mathrm{z}=1.2711$ \\
\hline \multirow{2}{*}{7} & Control $\beta$-catenin vs ER- $\alpha$ & $\mathrm{r}=0.896$ & $\mathrm{p} \leq 0.001^{*}$ \\
\hline & Cancer $\beta$-catenin vs ER- $\alpha$ & $\mathrm{r}=0.011$ & $\mathrm{z}=4.4520$ \\
\hline \multirow{2}{*}{8} & Control pGSK vs IGF-IR & $\mathrm{r}=0.849$ & $\mathrm{p}=0.0028^{*}$ \\
\hline & Cancer pGSK vs IGF-IR & $\mathrm{r}=0.279$ & $z=2.9853$ \\
\hline \multirow{2}{*}{9} & Control $\beta$-catenin vs IGF-IR & $\mathrm{r}=0.830$ & $\mathrm{p}=0.2218$ \\
\hline & Cancer $\beta$-catenin vs IGF-IR & $r=0.660$ & $\mathrm{z}=1.2217$ \\
\hline \multirow{2}{*}{10} & Control ER- $\alpha$ vs IGF-IR & $\mathrm{r}=0.846$ & $\mathrm{p}=0.001^{*}$ \\
\hline & Cancer ER- $\alpha$ vs IGF-IR & $\mathrm{r}=0.008$ & $\mathrm{z}=3.8134$ \\
\hline \multirow{2}{*}{11} & Control pGSK vs EGF-R & $\mathrm{r}=0.855$ & $\mathrm{p}=0.0944^{*}$ \\
\hline & Cancer pGSK vs EGF-R & $\mathrm{r}=0.625$ & $z=1.6728$ \\
\hline \multirow{2}{*}{12} & Control IKK- $\alpha$ vs EGF-R & $\mathrm{r}=0.885$ & $\mathrm{p}=0.0015^{*}$ \\
\hline & Cancer IKK- $\alpha$ vs EGF-R & $r=0.356$ & $\mathrm{z}=3.1711$ \\
\hline \multirow{2}{*}{13} & Control $\beta$-catenin vs EGF-R & $r=0.978$ & $\mathrm{p} \leq 0.0001^{*}$ \\
\hline & Cancer $\beta$-catenin vs EGF-R & $r=0.524$ & $\mathrm{z}=5.1536$ \\
\hline \multirow{2}{*}{14} & Control ER- $\alpha$ vs EGF-R & $\mathrm{r}=0.898$ & $\mathrm{p}=0.0001^{*}$ \\
\hline & Cancer ER- $\alpha$ vs EGF-R & $r=0.177$ & $z=3.964$ \\
\hline \multirow{2}{*}{15} & Control IGF-IR vs EGF-R & $\mathrm{r}=0.850$ & $\mathrm{p}=0.0426^{*}$ \\
\hline & Cancer IGF-IR vs EGF-R & $\mathrm{r}=0.153$ & $\mathrm{z}=2.027$ \\
\hline \multicolumn{4}{|c|}{ Breast Cancer } \\
\hline \multirow{2}{*}{1} & Cancer IKK- $\alpha$ vs IKK- $\beta$ & $\mathrm{r}=0.850$ & $\mathrm{p}=0.0007^{*}$ \\
\hline & Control IKK- $\alpha$ vs IKK- $\beta$ & $\mathrm{r}=0.153$ & $z=3.4055$ \\
\hline
\end{tabular}

r: Pearson correlation; p: Significance; z: Correlation co-efficient; ${ }^{*}$ Significant values.

molecule of Akt did not show any change in its expression or phosphorylation. GSK is deactivated by phosphorylation [23]. The absence of increase in pGSK suggests that GSK is active even though its levels did not change. However, $\beta$-catenin which is downstream to GSK is highly expressed in cancer samples. $\beta$-catenin increases proliferation in ER positive breast cancer cells by activating cyclin D1 ([9]. A previous study shows that higher expression of $\beta$-catenin along with p53 is correlated with worse survival [24]. Thus, signaling molecules downstream to Akt are highly expressed and activated in breast cancer tissues indicating abnormal activation of this pathway.
The role of p38 MAP kinase in cancer has been thought to occur through negative regulation of the cell cycle and senescence, suggesting that p38 MAPK is a tumor suppressor gene [25]. However, a recent study in MCF-7 breast cancer cell line shows that EGF-R phosphorylation leads to the activation of p38 mediated cell survival [26]. Previous study suggests that p38 activity was found to be upregulated in various carcinomas including that of the breast [27]. In the present study p38 is highly expressed in cancer tissue when compared with control indicating its role in breast cancer.

ER is often overexpressed in majority of in breast cancer along with IGF-IR. In this study, although $\operatorname{ER} \alpha$ 
levels were not significantly upregulated, it was elevated in $84.6 \%$ of the samples when compared with normal tissues. Previous study shows that ER $\alpha$ binds in an estrogen depended manner to the p $85 \alpha$ subunit of the PI3K, leading to the activation of Akt [28]. It is likely that in the ER positive patients Akt is activated via ER $\alpha$ but additional evidences are needed to confirm this possibility. Interestingly, AR was upregulated in a grade dependent manner with $75 \%$ of grade II and all of grade III samples showing upregulation.

AR upregulation has been shown in several earlier studies [18]. The upregulated AR expression may activate the p21 [29], which is a positive regulator of cell cycle. Previous study also suggests that $\mathrm{p} 21$ overexpression is associated with tumor metastasis in canine mammary tumours [30]. By this mechanism AR can insert the no genomic action through this pathway.

\section{Conclusion}

In conclusion, the present study shows that several signaling molecules are upregulated/activated in cancer tissues in a grade depended manner, and the pathway involving IGF-IR and Akt seems to be actively involved in breast cancer tissues. Signaling pathways important for cell survival involving Akt are highly activated in cancer samples. Further, there is a deregulation in the expression of signaling molecules in the cancer tissues when compared to the control samples.

\section{REFERENCES}

[1] E. Marshman and C. H. Streuli, "Insulin-Like Growth Factors and Insulin-Like Growth Factor Binding Proteins in Mammary Gland Function," Breast Cancer Research: $B C R$, Vol. 4, 2002, pp. 231-239. doi:10.1186/bcr535

[2] W. Ruan, V. Catanese, R. Wieczorek, M. Feldman and D. L. Kleinberg, "Estradiol Enhances the Stimulatory Effect of Insulin-Like Growth Factor-I (IGF-I) on Mammary Development and Growth Hormone-Induced IGF-I Messenger Ribonucleic Acid," Endocrinology, Vol. 136, No. 3, 1995, pp. 1296-302. doi:10.1210/en.136.3.1296

[3] H. M. Khandwala, I. E. McCutcheon, A. Flyvbjerg and K. E. Friend, "The Effects of Insulin-Like Growth Factors on Tumorigenesis and Neoplastic Growth," Endocrine ReViews, Vol. 21, No. 3, 2000, pp. 215-244. doi:10.1210/er.21.3.215

[4] M. Pollak, "Insulin-Like Growth Factor Physiology and Cancer Risk," European Journal of Cancer, Vol. 36, 2000, pp. 1224-1228. doi:10.1016/S0959-8049(00)00102-7

[5] A. Ouban, P. Muraca, T. Yeatman and D. Coppola, "Expression and Distribution of Insulin-Like Growth Factor-1 Receptor in Human Carcinomas," Human Pathology, Vol. 34, No. 8, 2003, pp. 803-808. doi:10.1016/S0046-8177(03)00291-0

[6] P. O. Hackel, E. Zwick, N. Prenzel and A. Ullrich, "Epi- dermal Growth Factor Receptors: Critical Mediators of Multiple Receptor Pathways," Current Opinion in Cell Biology, Vol. 11, No. 2, 1999, pp. 184-189. doi:10.1016/S0955-0674(99)80024-6

[7] H. W. Lo, S. C. Hsu, W. Xia, X. Cao, J. Y. Shih, et al., "Epidermal Growth Factor Receptor Cooperates with Signal Transducer and Activator of Transcription 3 to Induce Epithelial-Mesenchymal Transition in Cancer Cells via Up-Regulation of TWIST Gene Expression," Cancer ReSearch, Vol. 67, No. 19, 2007, pp. 9066-9076. doi:10.1158/0008-5472.CAN-07-0575

[8] Q. Ding, X. He, W. Xia, J. M. Hsu, C. T. Chen, et al., "Myeloid Cell Leukemia-1 Inversely Correlates with Glycogen Synthase Kinase-3Beta Activity and Associates with Poor Prognosis in Human Breast Cancer," Cancer Research, Vol. 67, No. 10, 2007, pp. 4564-4571. doi:10.1158/0008-5472.CAN-06-1788

[9] S. Y. Lin, W. Xia, J. C. Wang, K. Y. Kwong, B. Spohn, et al., "Beta-Catenin, a Novel Prognostic Marker for Breast Cancer: Its Roles in Cyclin D1 Expression and Cancer Progression," Proceedings of the National Academy of Sciences of the United States of America, Vol. 97, No. 8, 2000, pp. 4262-4266. doi:10.1073/pnas.060025397

[10] T. P. Garrington and G. L. Johnson, "Organization and Regulation of Mitogen-Activated Protein Kinase Signaling Pathways," Current Opinion in Cell Biology, Vol. 11, No. 2, 1999, pp. 211-218. doi:10.1016/S0955-0674(99)80028-3

[11] V. S. Sivaraman, H. Wang, G. J. Nuovo and C. C. Malbon, "Hyperexpression of Mitogen-Activated Protein Kinase in Human Breast Cancer," The Journal of Clinical Investigation, Vol. 99, No. 7, 1997, pp. 1478-1483. doi:10.1172/JCI119309

[12] F. Houle and J. Huot, "Dysregulation of the Endothelial Cellular Response to Oxidative Stress in Cancer," $\mathrm{Mo}$ lecular Carcinogenesis, Vol. 45, No. 6, 2006, pp. 362367. doi: $10.1002 / \mathrm{mc} .20218$

[13] Y. Cao and M. Karin, "NF-KappaB in Mammary Gland Development and Breast Cancer," Journal of Mammary Gland Biology and Neoplasia, Vol. 8, No. 2, 2003, pp. 215-223. doi:10.1023/A:1025905008934

[14] O. J. Finn, "Cancer Immunology," The New England Journal of Medicine, Vol. 358, No. 25, 2008, pp. 27042715. doi:10.1056/NEJMra072739

[15] D. Yee and A. V. Lee, "Crosstalk between the InsulinLike Growth Factors and Estrogens in Breast Cancer," Journal of Mammary Gland Biology and Neoplasia, Vol. 5, No. 1, 2000, pp. 107-115. doi:10.1023/A:1009575518338

[16] W. Schippinger, P. Regitnig, N. Dandachi, K. D. Wernecke, T. Bauernhofer, et al., "Evaluation of the Prognostic Significance of Androgen Receptor Expression in Metastatic Breast Cancer," Virchows Archiv: An International Journal of Pathology, Vol. 449, No. 1, 2006, pp. 24-30.

[17] E. O. Lillie, L. Bernstein and G. Ursin, "The Role of Androgens and Polymorphisms in the Androgen Receptor in the Epidemiology of Breast Cancer," Breast Cancer ReSearch: BCR, Vol. 5, No. 3, 2003, pp. 164-173. 


\section{doi:10.1186/bcr593}

[18] K. Hanley, J. Wang, P. Bourne, Q. Yang, A. C. Gao, et al., "Lack of Expression of Androgen Receptor May Play a Critical Role in Transformation from in Situ to Invasive Basal Subtype of High-Grade Ductal Carcinoma of the Breast," Human Pathology, Vol. 39, 2008, pp. 386-392. doi:10.1016/j.humpath.2007.07.007

[19] M. N. Pollak, E. S. Schernhammer and S. E. Hankinson, "Insulin-Like Growth Factors and Neoplasia," Nature Reviews. Cancer, Vol. 4, No. 7, 2004, pp. 505-518. doi:10.1038/nrc1387

[20] L. Mack, N. Kerkvliet, G. Doig and F. P. O’Malley, “Relationship of a New Histological Categorization of Ductal Carcinoma in Situ of the Breast with Size and the Immunohistochemical Expression of p53, c-erb B2, bcl-2, and ki-67," Human Pathology, Vol. 28, No. 8, 1997, pp. 974979. doi:10.1016/S0046-8177(97)90014-9

[21] L. P. Kane, M. N. Mollenauer, Z. Xu, C. W. Turck and A. Weiss, "Akt-Dependent Phosphorylation Specifically Regulates Cot Induction of NF-Kappa B-Dependent Transcription," Molecular and Cellular Biology, Vol. 22, No. 16, 2002, pp. 5962-5974. doi:10.1128/MCB.22.16.5962-5974.2002

[22] G. Gasparini, P. Boracchi, P. Bevilacqua, M. Mezzetti, F. Pozza and N. Weidner, "A Multiparametric Study on the Prognostic Value of Epidermal Growth Factor Receptor in Operable Breast Carcinom A," Breast Cancer Research and Treatment, Vol. 29, No. 1, 1994, pp. 59-71. doi:10.1007/BF00666182

[23] S. Frame and P. Cohen, "GSK3 Takes Centre Stage More than 20 Years after Its Discovery," The Biochemical Journal, Vol. 359, No. 1, 2001, pp. 1-16. doi:10.1042/0264-6021:3590001

[24] G. G. Chung, M. P. Zerkowski, I. T. Ocal, M. Dolled-
Filhart, J. Y. Kang, et al., "Beta-Catenin and p53 Analyses of a Breast Carcinoma Tissue Microarray," Cancer, Vol. 100, No. 10, 2004, pp. 2084-2092. doi:10.1002/cncr.20232

[25] T. M. Thornton and M. Rincon, "Non-Classical p38 Map Kinase Functions: Cell Cycle Checkpoints and Survival," International Journal of Biological Sciences, Vol. 5, No. 1, 2009, pp. 44-51.

[26] K. L. Mueller, K. Powell, J. M. Madden, S. T. Eblen and J. L. Boerner, "EGFR Tyrosine 845 Phosphorylation-Dependent Proliferation and Transformation of Breast Cancer Cells Require Activation of p38 MAPK," Translational Oncology, Vol. 5, No. 5, 2012, pp. 327-334.

[27] E. F. Wagner and A. R. Nebreda, "Signal Integration by JNK and p38 MAPK Pathways in Cancer Development," Nature Reviews. Cancer, Vol. 9, No. 8, 2009, pp. 537-549. doi:10.1038/nrc2694

[28] J. M. Renoir, V. Marsaud and G. Lazennec, "Estrogen Receptor Signaling as a Target for Novel Breast Cancer Therapeutics," Biochemical Pharmacology, Vol. 85, No. 4, 2013, pp. 449-465.

[29] J. P. Garay, B. Karakas, A. M. Abukhdeir, D. P. Cosgrove, J. P. Gustin, et al., "The Growth Response to Androgen Receptor Signaling in ERalpha-Negative Human Breast Cells Is Dependent on p21 and Mediated by MAPK Activation," Breast Cancer Research: BCR, Vol. 14, No. 1, 2012, p. R27. doi:10.1186/bcr3112

[30] R. Klopfleisch and A. D. Gruber, "Differential Expression of Cell Cycle Regulators p21, p27 and p53 in Metastasizing Canine Mammary Adenocarcinomas versus Normal Mammary Glands," Research in Veterinary Science, Vol. 87, No. 1, 2009, pp. 91-96. doi:10.1016/j.rvsc. 2008.12 .010 